\title{
Editorial: A Five-Year Update
}

\author{
Per Henning Uppstad, Atle Skaftun \& Oddny J. Solheim \\ Norwegian Reading Centre, University of Stavanger
}

October 1st 2020 is a milestone, as we count 5 years since the launch of Nordic fournal of Literacy Research. Since then it has become an important and acknowledged channel for publishing high quality studies, fulfilling the initial scope of publishing "rich pictures" of literacy settings in the Nordic countries. The development has been possible thanks to merited editorial board members serving as ambassadors and supporters to the journal, reviewers who have faithfully completed their tasks with high standards, and to researchers identifying the need for a publishing channel of this kind.

Nordic Fournal of Literacy Research has every year since it's beginning in 2015 had an increased number of publications. It started modestly in 2016 with only 7 publications, however in 2019 the result was 19 published peer-review articles.

Currently, there are over 30 articles active in the platform, all in different stages, and the number of published articles in 2020 will be very close to 20 . Thus far 11 peer reviewed articles have been published.

The view rating, a full text view of an article, has gone from about 2000 views of articles in 2016, to about 14000 views of articles in 2019. And now, in 2020 we are getting close to 20000 views of articles. The journal has more than 200 registered readers, but as the numbers show, the journal is read by a great number outside the registered readership.

From $2015-2020$ over 130 articles have been submitted, and the rejection rate is currently over $40 \%$.

The founding editors' intention was to take on the task for two years and then hand over the task to new editors. However, to establish a new journal of good quality was more time consuming and called for a longer time frame for the establishment. As we reach the 5 year anniversary, it is time to hand over the editorial responsibility to new scholars in the field, for the purpose of developing the journal further.

Professor Marte Blikstad-Balas (UiO) has been challenged to take on the task as editor-in-chief. Professor Gustaf B. Uno Skar (NTNU), Associate professor

\footnotetext{
^Correspondence: Per Henning Uppstad, email: per.h.uppstad@uis.no
} 
Michael Tengberg (KAU) and Associate professor Arild Michel Bakken (UiS) will serve as co-editors.

We have trust in the new editorial team's potential to maintain and develop NJLR's role in consolidating literacy as a research field in the Nordic countries. As part of establishing the new editorial team, some changes will be made in the editorial board. We would therefore like to thank all of you for your commitment and availability for the journal thus far. 